\title{
EFFECTS OF GIVING PEDADA FRUIT FLOUR (PFF) ON DIGESTA PROFILE AND SCFAS HYPERCHOLESTEROLEMIC RATS
}

\author{
Jariyah $^{* 1}$, Simon Bambang Widjanarko ${ }^{2}$, Yunianta ${ }^{2}$, Teti Estiasih ${ }^{2}$ \\ ${ }^{1}$ University of Pembangunan Nasional "Veteran"Jawa Timur, Surabaya, Indonesia \\ ${ }^{2}$ University of Brawijaya, Malang, East Java, Indonesia \\ E-mail : jariyahupn65@gmail.com
}

\begin{abstract}
Pedada Fruit Flour (PFF) contains $8.9 \%$ of pectin, it includes one type of soluble dietary fiber. It has hypocholesterelemic property. The effect of PFF to the digesta cholesterol profile, and production of SCFA (short chain fatty acids) has not been done before. The aim of this study is to determine the impact of giving PFF on digesta profile and short chain fatty acids (SCFAs). Twenty-five Wistar rats were divided into 5 treatment groups consist of two normal control, hypercholesterolemic group, and 3 treatment of hypercholesterolemic groups feed were supplemented with 3 , 6 and $9 \%$ PFF. Feeding was given for 28 days, on the $30^{\text {th }}$ day surgery was done to take the digesta, then performed an analysis of digesta profile includes weight, water content, cholesterol and SCFAs levels. The results showed that supplementation of 6 and 9\% PFF had significant effect on weight, water contents and cholesterol of digesta with the highest propionic: acetic acid ratio in the group treated with supplementation of 9\% PFF (0.46) followed by supplementation group $6 \%$ and $3 \%$ i.e., 0.41 and 0.38 , respectively. The ratio of propionic: acetic acid can reduce of serum cholesterol levels.
\end{abstract}

Keywords : PFF, digesta profile, SCFAs, hypercholesterolemic.

\section{INTRODUCTION}

Pedada Fruit Flour is a flour made from the pulp of mangrove spesies Pedada (Sonneratia caseolaris). The PFF soluble fiber content is higher than of seaweed species (Jariyah et al., 2013). Soluble fiber such as pectin in the digestive system has hypocholesterolemic effect and has the effect of resistance against coronary heart disease through a decrease in cholesterol (Suido et al.,2002). The PFF has been reported that it significantly decreases the total cholesterol, LDL cholesterol, triglycerides (Jariyah et al., 2013) and blood glucose (Jariyah et al., 2014).

Mechanism of dietary fiber lowers cholesterol, namely: inhibiting the absorption of cholesterol, lowering cholesterol transfer availability to the blood flow is reduced, preventing the synthesis of cholesterol, lowering the energy density of foods that reduce cholesterol synthesis and increasing the excretion of bile (Tim and Slavin, 2008). Maryanto et al., (2013), suggested that the mechanism of cholesterol reduction can be assessed by analyzing the SCFA (short chain fatty acids) and cholesterol digesta. SCFA is the result of fermentation of dietary fiber in the colon such as acetate, propionate and butyrate (Henningsson et al., 2002; Hijova and Chmelarova, 2007; Fotschki et al., 2014 ). Propionic acid after entering the bloodstream and liver can inhibit the action of the enzyme HMG-CoA reductase and reduce cholesterol synthesis (Lupton and Turner, 2000; Saravanan and Ignacimuthu, 2015). Meanwhile butyric acid is widely used as an energy source in colon and have antiinflammatory properties that are important for maintaining the health and healing of colon cells. Acetic acid plays a role in the synthesis of long-chain fatty acids, including cholesterol, glutamine, glutamate and betahydroxybutyrate, and can be used as an energy source (Syamsir, 2007; Topping, 1996). This study is a part of a previous research by Jariyah et al. (2013) and aims to determine the effect of PFF on digesta profile and SCFAs in hypercholesterolemic rats.

\section{METHODOLOGY}

Pedada fruit flour was mixed with AIN-93M standard feed as many as 3, 6 and $9 \%$ by Reeves et al. (1993) modified. Meanwhile high cholesterol feed has been made by previous researchers Jariyah et al. (2013). As measured research subjects as much as 25 male Wistar rats, cholesterol kit No. 10130 021, ether, acetic acid, propionate and butyrate standard.

Twenty-five male Wistar rats weighing $\pm 200 \mathrm{~g}$ were adapted for one week to be fed and watered adlibitum. Furthermore, mice were divided randomly into 5 groups, each group consisting of five rats. Group 1 was the positive control group (normal control), the other groups were conditioned hypercholesterolemia with high cholesterol fed. Group 2 was a group of hypercholesterolemic rats (negative control). Group 3, 4 and 5 were groups of hypercholesterolemic rats dosed with PFF in a standard feed by $3 \%, 6 \%$ and $9 \%$. Feeding was done for 28 days and on day 30 a surgery was done to take digesta. To be analyzed for water content, weight, cholesterol and SCFAs. Analysis of SCFAs included acetic acid, propionic and butyric using gas chromatography, whereas cholesterol analysis was performed using Liebermann-Burchard method with a spectrophotometer.The research was carried out after obtaining the Ethical Clearence from University of Brawijaya No. KEP-101-UB / 2012.

\section{Statistical Analysis}

Data were analyzed by One Way Anova SPSS V 16 with a confidence level of $5 \%$, followed by LSD test $5 \%$ to determine the differences between the treatment groups. 


\section{RESULTS AND DISCUSSIONS}

\section{The weight, water content and cholesterol leves in} ceacum digesta of rats

Feeding containing PFF showed a significant difference to the weight of the digesta rats $(p<0.05)$, as presented in Table 1. The weight of the digesta increased with increased dietary addition of PFF in the feed. The weight of digesta gained due to the increased PFF added, digesta weight of groups 5 was $6.3 \%(2.66 \pm 0.07)$, higher than that of group 3 and 4 . Likewise, the water content of the digesta showed that there was an increase in the group of rats with PFF $6 \%$ and $9 \%$, while the addition of $3 \%$ PFF gave no significantly difference with the standard feed group, the rising of water content was follwed by the increasing PFF added to the feed (Table 1).

PFF addition of $3 \%, 6 \%$ and $9 \%$ in the feed can increase cholesterol levels in digesta of rats significantly when compared to the group fed with the AIN-93M standard. The highest of cholesterol levels in digesta were found in the group with the addition of $9 \%$ PFF, followed by $6 \%, 3 \%$, hypocholesterolemic and normal control group i.e., $2.19 \% ; 1.91 \% ; 1.53 \% ; 1.05 \%$; and $0.94 \%$ respectively.

The increase in weight of the digesta prove that dietary fiber contained in the PFF affect the increased weight of the digesta. Insoluble fiber has a great ability to bind water so the digesta become heavier, while the soluble dietary fiber will increase the weight of digesta to bind fat and bile acids in the intestine to be issued together with feces. These results are similar with the results of research conducted by Jenkins et al., (1998) that the feeding resistant starch type 2 and 3 in rats may increase stool weight by $23 \%$.

Water content of the digesta incresed as added PFF was increased, it indicated that the effect of PFF fiber increased stool water in the gastrointestinal tract. Meier (2008) stated that fiber is necessary to maintain the normal funtioning of gastrointestinal tract in large bowel as prebiotic affect, dilution of colonic content, reduction in availability of toxins and bile acids, increase of flatulence and increase in stool water. Liong and Shah (2006) reported that the levels of faecal water increased along with the increase of feeding high fiber probiotics and sinbiotics.

The increased cholesterol levels in the digesta due to the addition of PFF dietary fiber contained in PFF able to bind cholesterol in the intestine, causing the accumulation of cholesterol, especially in the digesta which were removed together with feces. The more cholesterol is tied, the more cholesterol is also present in the digesta. The high levels of cholesterol showed the low absorption of cholesterol in the intestine (Lupton and Tumer, 2000). Zhou et al. (2015), repoted that dose response relationship between increased dietary fiber intake and dreased total cholesterol to HDL cholesterol

Table- 1. Weight, water content, and cholesterol levels in the digesta of rats during treatment

\begin{tabular}{|l|c|c|c|}
\hline \multicolumn{1}{|c|}{ Treatment } & $\begin{array}{c}\text { Weight of ceacum } \\
\text { digesta /day (g) }\end{array}$ & $\begin{array}{c}\text { Water Content of } \\
\text { ceacum digesta (\%) }\end{array}$ & $\begin{array}{c}\text { Cholesterol level of } \\
\text { ceacum digesta (\%) }\end{array}$ \\
\hline Normal control (Group. 1) & $0,92 \pm 0,06 \mathrm{~b}$ & $60,51 \pm 2,96 \mathrm{~b}$ & $0,94 \pm 0,06 \mathrm{~d}$ \\
\hline Hyperchol. control (Group 2) & $0,97 \pm 0,07 \mathrm{~b}$ & $59,37 \pm 4,32 \mathrm{~b}$ & $1,05 \pm 0,16 \mathrm{~d}$ \\
\hline Hyperchol.+ 3\% PFF (Group 3) & $1,21 \pm 0,11 \mathrm{~b}$ & $62,81 \pm 3,27 \mathrm{ab}$ & $1,53 \pm 0,05 \mathrm{c}$ \\
\hline Hyperchol.+6\% PFF (Group 4) & $1,73 \pm 0,10 \mathrm{a}$ & $64,74 \pm 3,34 \mathrm{a}$ & $1,91 \pm 0,03 \mathrm{~b}$ \\
\hline Hyperchol. + 9\% PFF (Group 5) & $2,66 \pm 0,07 \mathrm{a}$ & $67,26 \pm 5,59 \mathrm{a}$ & $2,19 \pm 0,16 \mathrm{a}$ \\
\hline
\end{tabular}

Different letters indicate differences in one column

Hyperchol.= Hypercholesterolemia

\section{Short Chain Fatty Acids (SCFAs) in the ceacum digesta of rats \\ The results of the short chain fatty acids} (SCFAs) composition in the digesta of rats on hypocholesterolemic effect are presented in Table 2. It showed that the administration of PFF has significant effect on levels of acetic, propionic and butyric acid $(\mathrm{p}<$ 0.05 ). The acetic and propionic acid content given of $3 \%$ PFF treatment (group 3) were lower than group 4 and 5.

SCFA which was obtained from dietary fiber fermentation in the gut of the cholesterol synthesis depends on the ratio of acetic acid and propionic acid in the blood vessels of the portal. Acetic and propionic acid first reaches the liver that affects the metabolism of carbohydrates and fats (Henningsson et al.,2002; Lupton and Turner, 2000).

The highest ratio of propionic : acetic acid in the cecum digesta SCFA components contained in the treatment of PFF addition of $9 \%(0.46)$ followed by groups of PFF $6 \% \quad(0.41)$, PFF $3 \% \quad(0.38)$, hypercholesterolemia (0.30), and normal group (0.26).
Cummings et al. (2001) reported that molar ratio of acetate : propionate : butyrate acid from fermentation of wheat and oat bran were $64: 16: 20$, from the fermentation of pectin was $80: 12: 8$, whereas for starch at $62: 15: 23$, while the non- starch polysaccharide type has a molar ratio of $63: 22: 8$. In general terms, acetate appears to contribute $50-60 \%$ of total SCFA while propionate and butyrate gave $20-24 \%$ and $15-20 \%$, respectively (Topping, 1996).

Short-chain fatty acids (SCFAs), especially propionate acid can decrease of serum cholesterol levels (Chen and Anderson, 1984; Wright et al., 1990; Bridges et al., 1990; Chen et al., 2003) The mechanism of cholesterol reduction by SCFAs fermented dietary fiber, especially propionic acid, was inhibited by the enzyme HMG-CoA reductase. This enzyme plays a role in the formation of mevalonate which is the main product in the formation of cholesterol, with the decreasing of the activity of the enzyme HMG-CoA, mevalonate would not be formed, along with cholesterol (Chen and Anderson, 1984; Saravanan and Ignacimuthu, 2015). Vuyst and Leroy 
(2011) stated that the butyrate acid has an important role against colon health, it has two functions i.e., as an energy source for the colonic epithelium and provides important effects on gene expression of colon cells. So it has known to have ability to inhibit the promotion phase of carcinogenesis (Bird et al., 2006; Kapkac et al., 2003).

Table-2. Composition of acetic, propionic and butyric acid in the digesta of rats after treated

\begin{tabular}{|l|c|c|c|c|}
\hline \multicolumn{1}{|c|}{ Treatment } & $\begin{array}{c}\text { Acetic Acid } \\
(\mathrm{mM})(\mathrm{A})\end{array}$ & $\begin{array}{c}\text { Propionic Acid } \\
(\mathrm{mM})(\mathrm{B})\end{array}$ & $\begin{array}{c}\text { Butyric Acid } \\
(\mathrm{mM})\end{array}$ & $\mathrm{B} / \mathrm{A}$ \\
\hline Normal control (Group1) & $76.32 \pm 11.34 \mathrm{a}$ & $18.78 \pm 2.10 \mathrm{ab}$ & $24.88 \pm 2.15 \mathrm{a}$ & $0.26 \pm 0.07$ \\
\hline Hyperchol.(Group 2) & $20.01 \pm 8,77 \mathrm{~b}$ & $6.48 \pm 3.74 \mathrm{c}$ & $5.63 \pm 3.42 \mathrm{c}$ & $0.30 \pm 0.06$ \\
\hline Hyperchol.+3\% PFF (Group 3) & $11.06 \pm 1.34 \mathrm{bc}$ & $4.28 \pm 0.89 \mathrm{c}$ & $5.24 \pm 1.23 \mathrm{c}$ & $0.38 \pm 0.03$ \\
\hline Hyperchol.+6\% PFF (Group 4) & $36.20 \pm 8.77 \mathrm{c}$ & $14.27 \pm 1.75 \mathrm{~b}$ & $14.81 \pm 2.11 \mathrm{~b}$ & $0.41 \pm 0.05$ \\
\hline Hyperchol. +9\% PFF (Group 5) & $51.31 \pm 5.72 \mathrm{c}$ & $23.52 \pm 1.45 \mathrm{a}$ & $12.33 \pm 1.74 \mathrm{~b}$ & $0.46 \pm 0.02$ \\
\hline
\end{tabular}

Differences letter stating the difference in one column .

Hyperchol.= Hypercholesterolemia

\section{CONCLUSIONS}

In conclusion, this study on rats fed with PFF on feed during 4 weeks treatment was able to give effect on increased of weight, water content and cholesterol in feses together with the propinic acid ratio of SCFAs composition ceacum digesta of rats, so that it can be used as an alternative to decrease cholesterol.

\section{REFERENCES}

Bird A.R., Brown I.L. and Topping D.L. 2006. Low and high amylose maize starches acetylated by a commercial or a laboratory process both deliver acetate to the large bowel of rats. Food Hydrocolloids, 20 (8): 1135-1140.

Bridges S.R., Anderson J.W., Deakins D.A. and Wood C.A. 1990. Oat bran increases serum acetate of hypocholesterolemic men. American Journal of Clinical Nutrition, 56: $455-459$.

Chen H.L., Wang C.H., Chang C.T. and Wang T.C. 2003. Effects of Taiwanese Yam (Dioscorea japonica Thunb. Var. pseudojaponica Yamamoto) on Upper Gut Function and Liipid Metabolism in Balb/cMice. Basic Nutritional Investigation. Nutrition, 19:646-651.

Chen W.J. and Anderson J.W. 1984. Propionate may mediated the hypocholesterolemic effects of certain soluble plant fibers in cholesterol-fed rats. Proceedings of the Society for Experimental Biology and Medicine, 175: 225-218.

Cummings J.H., Mcfarlane G.T. and Englyst H.N. 2001. Prebiotic digestion and fermentation. American Journal of Nutrition, 415-420.

Henningsson A.M., Bjorck I.M.E and Nyman M.G.L. 2002. Combinations of indigestible carbohydrates affect short-chain fatty acid formation in the hindgut of rat. Journal of Nutrition, 132: 3098-3104.

Hijova E. and Chmelarova A. 2007. Short chain fatty acids and colonic health. Bratisi Lek listy, 108 (80) : 354358 .
Fotschki B., Jurgoński A., Juśkiewicz J., Kołodziejczyk K. and Sójka M. 2014. Effects of Dietary Addition of a LowPectin Apple Fibre Preparation on Rats. Polish Journal of Food Nutrition Sciences, 64( 3): 193-199.

Jariyah, Azkiyah L., Widjanarko S.B., Estiasih T., Yuwono S.S and Yunianta. 2013. Hypocholesterolemic effect of Pedada (Sonneratia caseolaris) fruit flour in wistar rats. International Journal of PharmTech Research, 5(4): 1619-1627.

Jariyah, Widjanarko S.B., Yunianta and Estiasih T. 2014. Hypoglycemic effect of Pedada (Sonneratia caseolaris) Fruit Flour (PFF) in alloxan-induced diabetic rats International Journal of PharmTech Research, 7(1) : 3140 .

Jenkins D.J.A., Vuksan C ., Kendall W.C., Wursch P., Jeffcoat R., Waring S. and Wong E.1998. Physiological effects uf resistant starches on fecal bulk, short chain fatty acids, blood lipids and glycemic index. Journal of American College of Nutrition, 17(6): 609-616.

Kapkac M., Erikoglu M., Tuncyurek P., Ersin S., Esassolak M., Alkanat M. and O. Sipahioglu. 2003. Fiber enriched diets and radiation induced injury of the gut. Nutrition Research, 23: 77-83.

Liong M.T. and Shah N.P .2006. Effects of a Lactobacillus casei synbiotic on serum lipoprotein, intestinal microflora, and organic acids in rats. Journal of Dairy Science, 81:1390-1399.

Lupton J.R. and Turner D. 2000. Dietary Fiber, In Biochemical and Physiological Aspects of Human Nutrition. London: WB Sounders Company.

Maryanto S., Fatimah S., Sugiri and Marsono Y. 2013. The effect of red guava fruits supplementation on the SCFA and cholesterol production in caecum of hypercholesterolemic rats. AGRITECH, 33 (3):334-339.

Meier R.F. 2008. Basic in clinical nutrition: Fiber and short chain fatty acids. The European e-Journal of Clinical Nutrion and Metabolism, xx : 1-3. 
Reeves P.G., Nielsen F.H. and Fahey G.C.1993. AIN-93 Purified diets for laboratory rodents: final report of the American Institute of Nutrition Ad Hoc Writing Committee on the formulation of the AIN-76A rodent diet. American Institute of Nutrition. Journal of Nutrition, 123: 1939-1951.

Saravanan M and Ignacimuthu S. 2015. Hypocholesterolemic Effect of Indian Medicinal Plants A Review. Medical Chemistry, 5(1):40-49.

Suido H., Tanaka T ., Tabei, Takeuchi A., Okita M., Kishimoto T., Kasayama S. and Higashino K. 2002. A mixed green vegetable and fruit bererage decreased the serum level of low- density lipoprotein cholesterol in hypercholesterolemic patients. Journal Agricultural and Food Chemistry, 50 (11): 3346-3350.

Syamsir E. 2007. Function to diet of SCFAs for health. Elvira_itp's blog. It was accessed on August 1, 2014.

Tim D.A. and Slavin J.L. 2008. Dietray fiber and the relationship to chonic diseases. American Journal of Lifstyle Medicine, 2:233.
Topping D.L. 1996. Short chain fatty acids produced by intestinal bacteria. Asia Pacific Journal Clinical Nutrition, 5:15-19.

Vuyst L.D. and Leroy F. 2011. Cross-feeding between Bifidobacteria and butyrate producing, colon bacteria expalins bifidobacterial competitiveness, butyrate production, and gas production. International Journal of Food Microbiology, 149 (1): 73-80.

Wright R.S., Anderson J.W. and Bridges S.R. 1990. Propionate inhibits hepatocyte lipid synthesis. Proceedings of the Society for Experimental Biology and Medicine., 195: 29

Zhou Q., Jiang Wu, Jie Tang, Jia-Ji Wang, Chu-Hong Lu and Pei-Xi Wang .2015. Beneficial Effect of Higher Dietary Fiber Intake on Plasma HDL-C and TC/HDL-C Ratio among Chinese Rural-to-Urban Migrant Workers. International Journal of Environmental Research Public Health, 12:4726-4738. 